\title{
An Analysis of Iron Flux Bridges Topologies for 12Slot-14Pole HE-FSM
}

\author{
Siti Khalidah Rahimi ${ }^{1,}$, Md. Zarafi Ahmad ${ }^{2}$, Erwan Sulaiman ${ }^{2}$ and S.M.N.S.Othman ${ }^{1}$ \\ ${ }^{1}$ Research Center for Applied Electromagnetics (EMCenter), Universiti Tun Hussein Onn Malaysia, \\ Batu Pahat, Malaysia \\ ${ }^{2}$ Dept. of Electrical Power Engineering, FKEE Universiti Tun Hussein Onn Malaysia, Batu Pahat, \\ Malaysia
}

\begin{abstract}
In this paper, a novel Hybrid Excitation Flux Switching Machine (HE-FSM) with DC-field excitation coil (DC-FEC) wounded in radial direction is proposed. The design is able to generate high torque and power performance because of a few points of interest such as robust rotor structure, non-overlapping windings and reduction of flux cancellation in stator yoke. However, the design with FEC in radial direction required no space between upper FEC and outer stator of machine which is lead to flux loss to surrounding area and flux saturation in stator yoke. As a solution, iron flux bridges have been introduced on the stator core to produce high torque execution. By using JMAG Designer ver. 14, numerous configuration of iron flux bridges have been presented and overviewed. Then, performances of torque at numerous flux bridges is analysed and compared. A design with highest torque is chosen to investigate the other performances of the machine.
\end{abstract}

\section{Introduction}

Principal idea of Flux Switching Machine (FSM) has been introduced and reported in the year 1950. [1-2]. Over the last decade, there are numerous novelty and several of the design have been applied for different applications, running from minimal effort residential machines, car, wind power, aviation, and etc. Generally, a typical FSM such as Permanent Magnet-FSM (PM-FSM), Field Excitation- FSM (FE-FSM), and Hybrid Excitation- FSM (HE-FSM) are categorised as shown in Fig. 1.

PM-FSM and FE-FSM only have a single main flux source for the motor to operate, one of the source comes from the permanent magnet (PM) itself and the other is the field excitation coil (FEC). As for HE-FSM, it require flux source from the PM and FEC, respectively as their main flux sources [3]. PM-FSM exhibit a high torque density and high efficiency meanwhile the price of PM material is high. In addition, the operating temperature of PM itself may restrict its application and performance. At high speed operation, the fluxweakening operation affected the PM machines due to fixed excitation

${ }^{*}$ Corresponding author : sitikhalidah17@gmail.com 


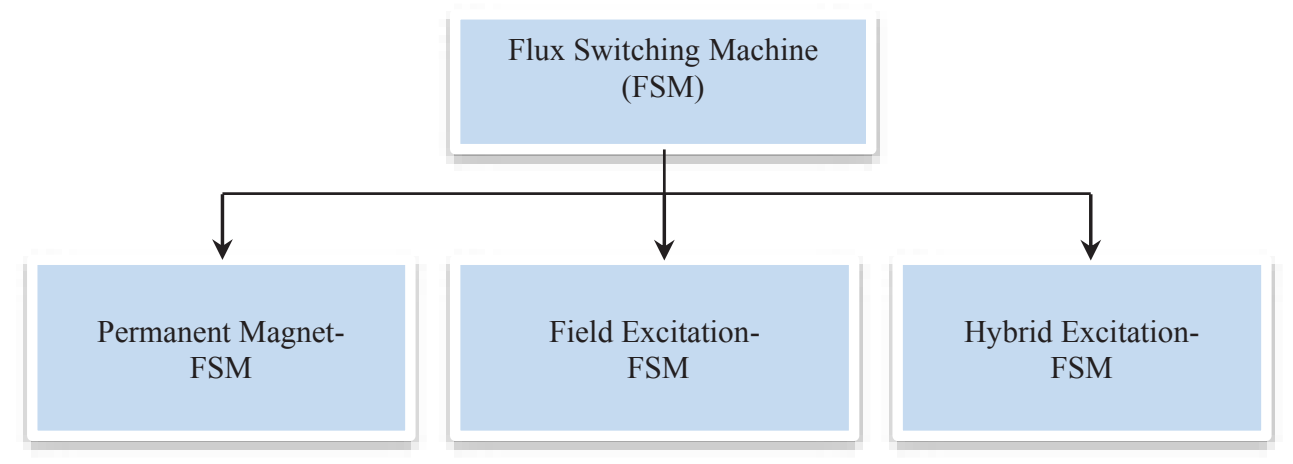

Fig. 1. Three categories of Flux Switching Machine (FSM)

from PM only. To overcome the high cost, PM excitation can be replaced with the FEC to form a FE-FSM.

FE-FSM is a model quite similar to salient-rotor reluctance machine with its own novel topology, by combining the principles of the Switch Reluctance Motor (SRMs) and inductor generator [4]. Theoretically, FE-FSM involve switching the flux vector with the armature coil winding, which relate to the rotor tooth position respectively. This type of machine has the potential of low cost and variable flux capabilities suitable for different performances [5]. Furthermore, the design structure is simple, easy to construct and no PM required. However, single-phase FE-FSM has issues of high torque ripple, low pull-up torque and one way rotating direction only. Then, armature coil and FEC windings are overlapped to each other resulting high copper loss [6].

Furthermore, HE-FSM is introduced as another option by bringing together the advantages of both PM machines and DC FEC synchronous machines. Therefore, the machine can possibly improve the output torque and power, enhance flux weakening capability, flux control capability and increase its efficiency [7-9]. Numerous combinations of rotor pole and stator slot for HE-FSM have been studied and promote for high-speed application such as 12S-10P HE-FSM configuration is proposed with a separated PM and Ctype stator core, however this design is difficult to manufacture [10-11]. In order to decrease the supply frequency of the inverter, a design with 6S-5P HE-FSM has been proposed.

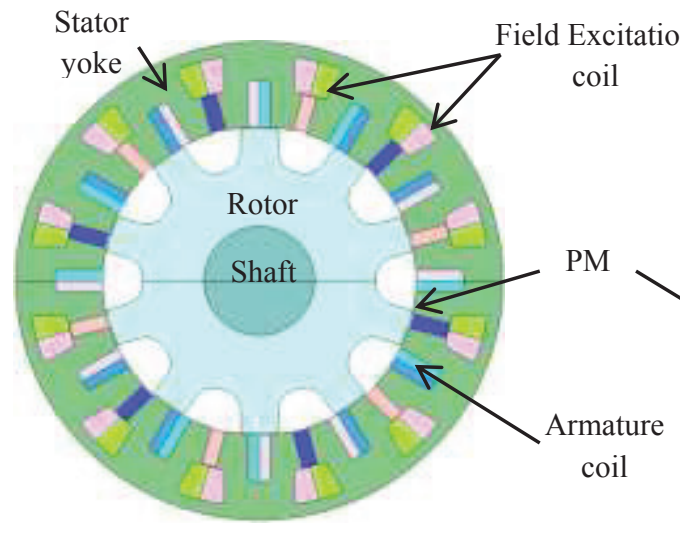

(a)
Stator

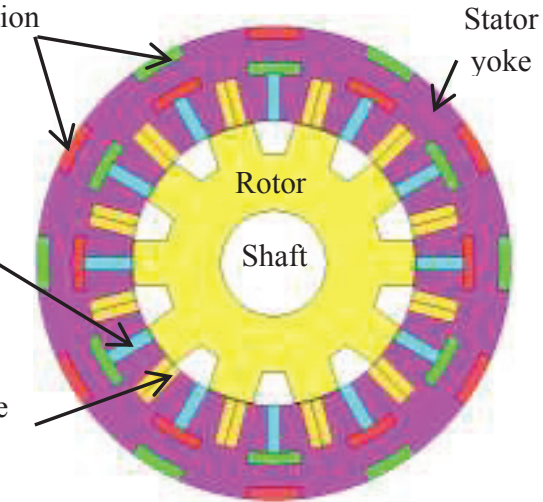

(b)

Fig. 2. The design comparison of 12Slot HE-FSM (a) Theta direction (b) Radial direction 
Previously, all HE-FSM design have arranged their armature coil and FEC in thetha direction which create an issue of flux cancellation between PM flux and FEC flux. Thus, a new design of HE-FSM with arrangement of DC FEC in radial direction is introduced to overcome high flux cancellation. The design comparison of 12Slot HE-FSM with FEC in theta direction and radial direction is shown in Fig. 2(a) and Fig. 2(b), respectively [3]. In this paper, performance analysis is carried out for numerous iron flux bridges topologies of 12Slot-14Pole HE-FSM with DC FEC in radial polarity. The performance of selected design is also discussed.

\section{Design restrictions, specifications and parameter of 12 Slot 14Pole HE-FSM}

Parameter specifications and dimensions of the proposed 12Slot-14Pole HE-FSM are listed in Table 1 and Table 2, respectively. Electrical restrictions related with the inverter has a maximum $650 \mathrm{~V}$ DC bus voltage and maximum of $30 \mathrm{~A} / \mathrm{mm}^{2}$ and $30 \mathrm{~A}_{\mathrm{rms}} / \mathrm{mm}^{2}$ for DC FEC winding and armature winding, respectively. Additionally, the dimensions of the proposed HE-FSM such as outer diameter of the stator and shaft radius are set to $269 \mathrm{~mm}, 30 \mathrm{~mm}$ respectively where air gap is set at $0.7 \mathrm{~mm}$. Besides, the weight of PM has been kept constant at $1.3 \mathrm{~kg}$.

For the motor dimension in Table 2, rotor parameters specified as outer rotor radius, L1, rotor tooth depth, L2 and rotor tooth width, L3 fixed at $80.25 \mathrm{~mm}, 20.2 \mathrm{~mm}$ and $9.5 \mathrm{~mm}$, respectively. Moreover, the PM depth, L4 is firmed at $26.775 \mathrm{~mm}$. For DC FEC parameters, DC FEC width and depth, L5 and L6 are fixed at $29.98 \mathrm{~mm}$ and $6.67 \mathrm{~mm}$, respectively with 60 turns of DC FEC coil. Lastly, the armature coil parameter such as armature coil width and armature coil depth, L7 and L8, are set to $6.46 \mathrm{~mm}$ and $26.775 \mathrm{~mm}$, respectively, this gives the 7 number of turns for armature coil [3].

Table 1. HE-FSM design restriction and specification for HEV

\begin{tabular}{|c|c|}
\hline Description & HE-FSM \\
\hline Max. DC-bus voltage inverter $(\mathrm{V})$ & 650 \\
\hline Max. inverter current $\left(\mathrm{A}_{\mathrm{rms}}\right)$ & 360 \\
\hline Max. current density in armature winding, $\mathrm{J}_{\mathrm{a}}\left(\mathrm{A}_{\mathrm{rms}} / \mathrm{mm}^{2}\right)$ & 30 \\
\hline Max. current density in excitation winding, $\mathrm{J}\left(\mathrm{A} / \mathrm{mm}^{2}\right)$ & 30 \\
\hline Stator outer diameter $(\mathrm{mm})$ & 269 \\
\hline Motor stack length $(\mathrm{mm})$ & 84 \\
\hline Shaft radius $(\mathrm{mm})$ & 30 \\
\hline Air gap length $(\mathrm{mm})$ & 0.7 \\
\hline PM weight $(\mathrm{kg})$ & 1.3 \\
\hline Maximum speed $(\mathrm{r} / \mathrm{min})$ & 20000 \\
\hline Maximum torque $(\mathrm{Nm})$ & 303 \\
\hline Maximum power $(\mathrm{kW})$ & 123 \\
\hline
\end{tabular}

Table 2. Dimension of HE-FSM

\begin{tabular}{|c|c|c|}
\hline \multirow{2}{*}{ Parameter } & Details & HE-FSM \\
\cline { 2 - 3 } & PM volume $(\mathrm{kg})$ & 1.3 \\
\hline P1 & Rotor radius $(\mathrm{mm})$ & 80.25 \\
\hline P2 & Rotor pole depth $(\mathrm{mm})$ & 20.2 \\
\hline P3 & Rotor pole width $(\mathrm{mm})$ & 9.33 \\
\hline P4 & PM height $(\mathrm{mm})$ & 26.775 \\
\hline
\end{tabular}




\begin{tabular}{|c|c|c|}
\hline P5 & FEC width $(\mathrm{mm})$ & 29.98 \\
\hline P6 & FEC height $(\mathrm{mm})$ & 6.67 \\
\hline P7 & Armature coil width $(\mathrm{mm})$ & 6.46 \\
\hline P8 & Armature coil height $(\mathrm{mm})$ & 26.775 \\
\hline $\mathrm{Na}$ & No. of turns of AC & 7 \\
\hline $\mathrm{Ne}$ & No. of turns of FEC & 60 \\
\hline
\end{tabular}

Besides, in 2D-Finite Element Analysis (FEA) analysis, JMAG-Designer ver.14.1, released by Japanese Research Institute (JRI) is used for this design. In case of PM, Neodiyum-Ferrite-Boron based on Neomax-35AH material is used, its residual flux density and coercive force at $20 \mathrm{C}^{\circ}$, is $1.2 \mathrm{~T}$ and $932 \mathrm{kA} / \mathrm{m}$. The chosen electrical steel that is utilized for rotor and stator is $35 \mathrm{H} 210$. Based on Fig. 3, it demonstrates the initial design of DC FEC in radial direction for 12Slot-14Pole HE-FSM.

\section{Numerous iron flux bridges topologies}

The new HE-FSM is known as HE-FSM with radial direction since the FEC positioned is below and upper to each other in the stator. Meanwhile, the flux generated by FEC cannot flow through upper FEC because no space provide at this part. This phenomena leads to less flux generated in the machine. By adding iron flux bridges at upper FEC, the flux can flow easily and flux generation can be increased as compare to the design without iron flux bridges. Moreover, it can embellish the performance of the FEC with several flux excitation level. Several arrangements of $1 \mathrm{~mm}$ thickness of iron flux bridges are designed to the proposed in HE-FSM as highlight in Fig. 4. The presence of FEC winding, PMs and iron flux bridges in stator can vary the machine performance in terms of PM magnetic flux at no load condition, excitation current utilization, toque capability and so on.

From the figure, A1 shows the initial configuration of the proposed design in the absence of iron flux bridge, which partially affects flux leakage from both outer and inner stator core to the air gap. Meanwhile, A2, A3, and A4 demonstrate different arrangements of a $1 \mathrm{~mm}$ iron flux bridge placed between FEC slot-top layer of stator core, FEC slot and PM, finally between PM and rotor air gap, respectively. It is clear from the figure, that for A2 and A3 condition, a flux drainage occurs from PM to air gap. For A4 condition, a flux leakage occur and results in flux loss to outer region of the stator. Furthermore, there is two more possible combination of a $1 \mathrm{~mm}$ iron flux bridges situated between PM, FEC slot and stator, known as A5 and A6.

Although, at this configuration, overall flux has been reduce since the flux oppose from one bridge to another, which causes reduction of total performance of the machine. Torque performances of all iron flux bridge arrangement are analyzed and the maximum torque obtained are recorded as shown in Fig. 5. It is clear that, in case of A2 configuration, highest torque has been achieved which is approximately $221 \mathrm{Nm}$. For the lowest torque, $194.06 \mathrm{Nm}$ is obtained for A4 configuration. It is because there exist a flux drainage and elimination occur at the air gap as well as flux flows to outer most part of the stator core. Since A2 gives the highest maximum torque output, the performances of A2 configuration in load condition in term of torque and power with respect to various armature current density, $\mathrm{J}_{\mathrm{a}}$ and field excitation current density, $\mathrm{J}_{\mathrm{e}}$ conditions are analyzed and discussed. 


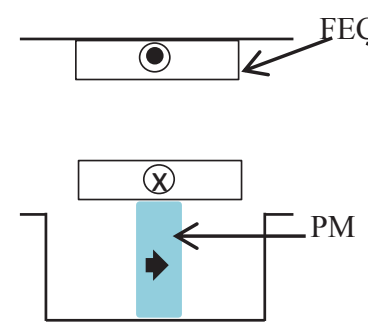

A1

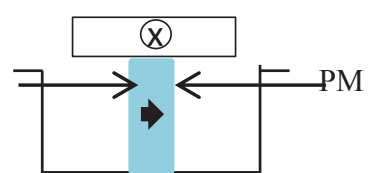

A2
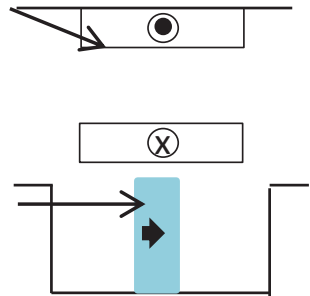

A3
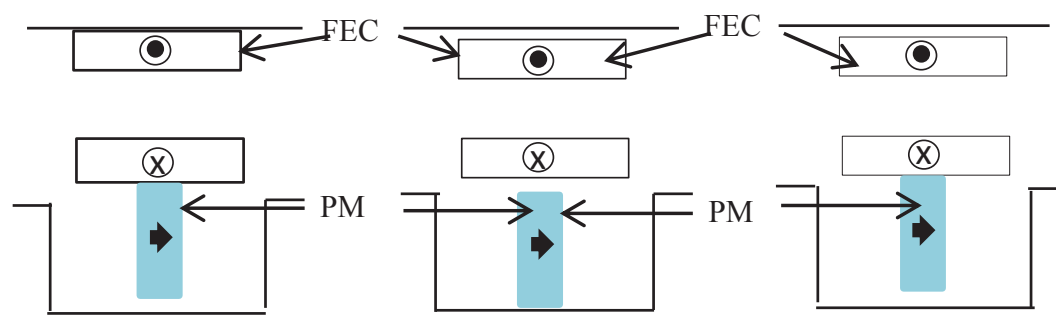

A5

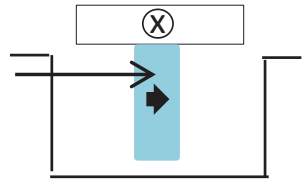

A6

Fig. 3. The arrangement of iron flux bridges

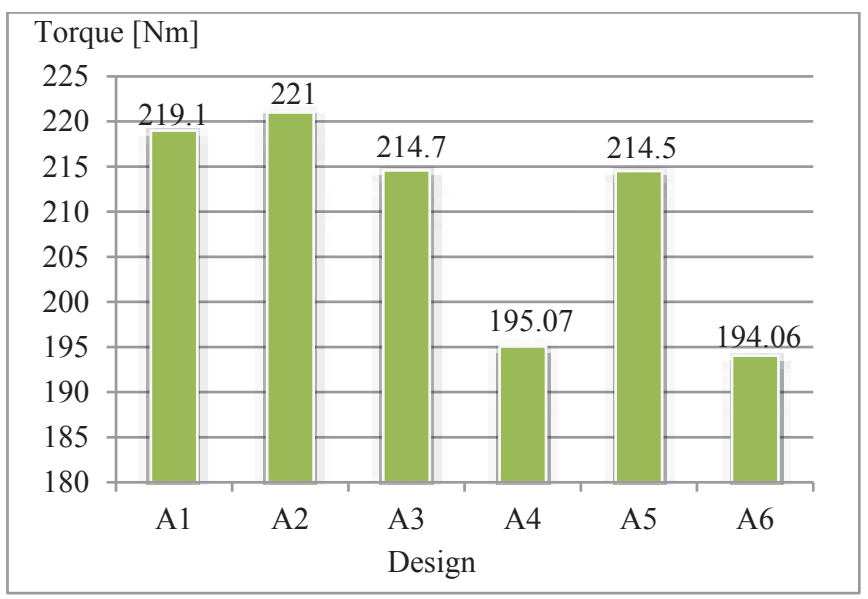

Fig. 4. The maximum torque for all configuration

\section{Performance of A2 design}

The instantaneous torque waveform of 12Slot-14Pole HE-FSM with A2 configuration are plotted in Fig. 5, based on 2D-FEA at maximum current density condition, of $30 \mathrm{~A} / \mathrm{mm}^{2}$ and $30 \mathrm{~A}_{\mathrm{rms}} / \mathrm{mm}^{2}$ for DC FEC and armature coil, respectively. From the figure, it is clear that the average torque reaches $221.4 \mathrm{Nm}$ with peak-to-peak of $20 \mathrm{Nm}$. Since the peak-to-peak torque of A2 design is quite low, it is expected that the machine produce low vibration and noise in practical applications.

Furthermore, Fig. 6 represents the torque versus $\mathrm{J}_{\mathrm{e}}$ at various $\mathrm{J}_{\mathrm{a}}$ characteristics. Both $\mathrm{J}_{\mathrm{e}}$ and $\mathrm{J}_{\mathrm{a}}$ are varied from 0 to $30 \mathrm{~A} / \mathrm{mm}^{2}$ and $30 \mathrm{~A}_{\mathrm{rms}} / \mathrm{mm}^{2}$. It is examined that the torque 
increased as $\mathrm{J}_{\mathrm{a}}$ and $\mathrm{J}_{\mathrm{e}}$ increased. Additionally, the increment of the torque shows the machine possible to be applied for higher current density condition. This feature gives huge advantages of the HE-FSM which is suitable for wide range applications [12]. However, the torque remains constant after a certain limit even it is at higher $\mathrm{J}_{\mathrm{a}}$. From the graph, the maximum torque obtained $221 \mathrm{Nm}$ when $\mathrm{J}_{\mathrm{a}}$ and $\mathrm{J}_{\mathrm{e}}$ are set to maximum.

Graph of power versus maximum armature current density, $\mathrm{J}_{\mathrm{a}}$ at various $\mathrm{J}_{\mathrm{e}}$ is analyzed and depicted in Fig. 7. From the figure, it shows that the power increased linearly with increasing of DC FEC current density, Je. The maximum power output is approximately $95.14 \mathrm{~kW}$ at maximum armature and FE current density.

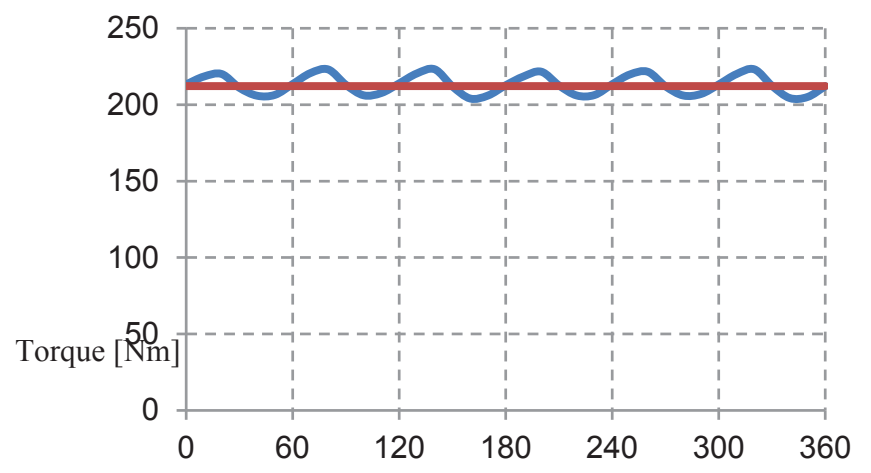

Fig. 5. Instantenous torque for $A 2$

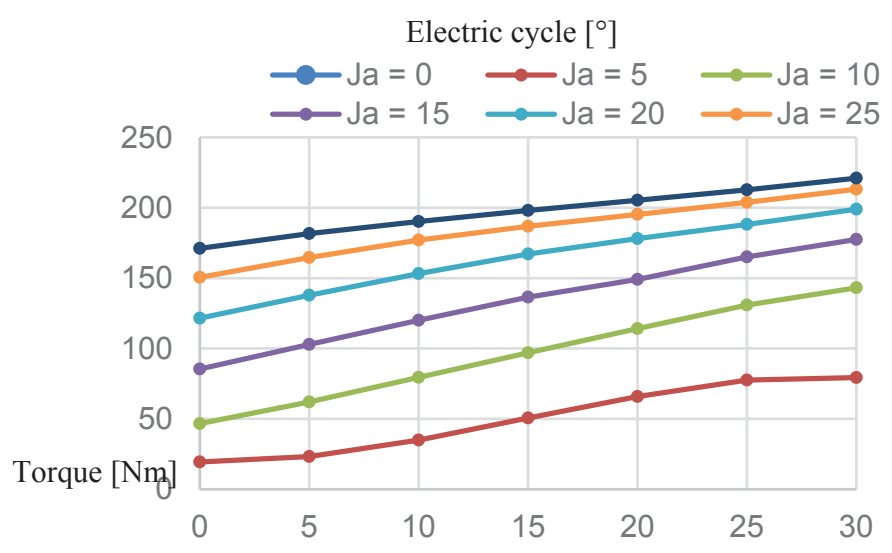

Fig. 6. Torque versus $\mathrm{J}_{\mathrm{e}}$ at various $\mathrm{J}_{\mathrm{a}}$ characteristics for $\mathrm{A} 2$

Je $\left[\mathrm{A} / \mathrm{mm}^{2}\right]$ 


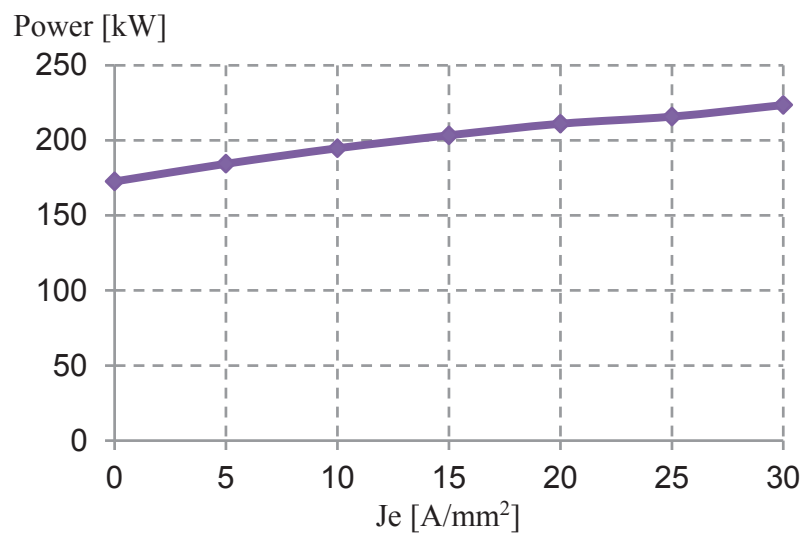

Fig. 7. Power versus $J_{e}$ at maximum $J_{a}$ for $A 2$

\section{Conclusions}

As a conclusion, numerous design or topologies of the iron flux bridges for 12Slot-14Pole HE-FSM have been overviewed and discussed. The iron flux bridges with $1 \mathrm{~mm}$ thickness are introduced on the initial design in order to solve some drawbacks of the previous design and improve the capability of the FEC with various excitation levels. Moreover, configuration A2 with a single iron flux bridge located between upper FEC slot and outer stator produces higher torque compared with other configuration, which is approximately $221 \mathrm{Nm}$. Finally, the performance of the instantaneous torque, torque and power have been analysed.

\section{Acknowledgements}

This work was supported by GPPS (Vot. U714) and IGSP (Vot. U683) under Ministry of Education Malaysia, and Universiti Tun Hussein Onn Malaysia (UTHM), Batu Pahat, Johor, Malaysia.

\section{References}

1. Z. A. Husin, E. Sulaiman, F. Khan and M. F. Omar, Performances comparison of $12 S-$ $14 P$ field excitation flux switching motor with overlap and non-overlap windings for hybrid electric vehicles, IEEE Student Conference on Research and Development, $p p$. 1-6 (2014)

2. E. Sulaiman, S. N. U. Zakaria and T. Kosaka, Parameter sensitivity study for optimization of single phase E-Core hybrid excitation flux switching machine, IEEE International Conference on Mechatronics (ICM),pp. 697-702 (2015).

3. S. K. Rahimi and E. Sulaiman, Design investigation of hybrid excitation flux switching machine for high-speed electric vehicles, IEEE 8th International Power Engineering and Optimization Conference (PEOCO), pp. 303-307 (2014).

4. E. Sulaiman, T. Kosaka and N. Matsui, A novel hybrid excitation flux switching synchronous machine for a high-speed hybrid electric vehicle applications, International Conference on Electrical Machines and Systems, pp. 1-6 (2011).

5. E. Sulaiman, T. Kosaka and N. Matsui, A novel hybrid excitation flux switching synchronous machine for a high-speed hybrid electric vehicle application, International Conference on Electrical Machines and Systems, pp. 1-6 (2011). 
6. M. Z. Ahmad, E. Sulaiman, F. Khan and Z. A. Haron,, Design and performance analysis of 12Slot-14Pole HE-FSM with outer-rotor configuration, IEEE 8th International Power Engineering and Optimization Conference (PEOCO), pp. 369-374 (2014).

7. M. M. A. Mazlan, E. Sulaiman, M. Z. Ahmad and S. M. N. S. Othman, Design optimization of single-phase outer-rotor hybrid excitation flux switching motor for electric vehicles, IEEE Student Conference on Research and Development, pp. 1-6 (2014).

8. H. Ali, E. bin Sulaiman, M. Jenal and M. F. Omar, Three phase segmental rotor hybrid excitation flux switching motors for various applications, IEEE Student Conference on Research and Development (SCOReD), pp. 373-377 (2015).

9. E. Sulaiman, T. Kosaka and N. Matsui, A novel hybrid excitation flux switching synchronous machine for a high-speed hybrid electric vehicle applications, International Conference on Electrical Machines and Systems, pp. 1-6 (2011).

10. M. K. Hassan, E. Sulaiman, G. M. Romalan, M. F. Omar and M. Jenal, Load analysis of dual Rotor Hybrid Excitation Flux Switching Machine (DR-HE-FSM), IEEE Conference on Energy Conversion (CENCON), pp. 155-159 (2015).

11. N. A. Jafar and E. Sulaiman, Design analysis of $12 S-10 P$ hybrid-excitation fluxswitching permanent-magnet machines for hybrid electric vehicle, IEEE 8th International Power Engineering and Optimization Conference (PEOCO2014), pp. 308312 (2014).

12. M. M. A. Mazlan, E. Sulaiman, M. Z. Ahmad and S. M. N. S. Othman, Topologies of single-phase outer-rotor hybrid excitation flux switching motor for in wheel drive applications, IEEE Conference on Energy Conversion (CENCON), pp. 112-116 (2014). 